\title{
A função dos jardins botânicos nos dias atuais*
}

* Palestra proferida pelo Prof. Dr. Luiz Emydio de Mello Filho, durante a comemoração do aniversário do Jardim Botânico, a 13-6-1984.

São discutidos os conceitos de jardim e de "Jardim Botânico". São definidos os parâmetros que definem o jardim como uma modalidade de paisagem construída ou antrópica, respectivamente as finalidades utilitária, lúdica ou cognitiva. $E$ feito um aprofundamento do conceito de "Jardim Botânico" distinguindo-o de outra modalidade de jardim, o "Jardim Zoológico", dando-se ênfase à presença de uma coleção de plantas. como fundamental para sua categorização. É apresentado numa resumida digressão sobre os jardins da Antiguidade no qual é mencionado o filósofo grego Aristóteles como o fundador do primeiro "Jardim Botânico". São mencionados os Jardins monásticos da ldade Média e é citada a fundação do primeiro "Jardim Botânico" moderno em 1544, em Pisa, por Luca Ghini, professor da universidade local. É dada uma cronologia do estabelecimento de outros importantes "Jardins Botânicos" na Europa. Na América são destacados os Jardins Botânicos, existentes no México, conforme encontrados pelo conquistador espanhol e o papel de Príncipe Maurício de Nassau, como fundador do primeiro "Jardim Botânico", do primeiro Observatório Astronômico e do primeiro "Jardim Zoológico" das Américas, pós-descobrimento. $O$ artigo é conclurdo com uma exposição das finalidades de um "Jardim Botânico", na atualidade, a saber as finalidades utilitária, lúdica e educativa.

O Jardim Botânico é uma categoria de jardim possuidora de atributos especiais que o caracterizam e distinguem das demais classes de jardins. jardim?

Mas que vem a ser, em realidade, um

A dar crédito às versões bíblicas foi o jardim a obra inicial do Criador, do DeusArquiteto que o fez já exercendo a função de vegetação protetora dos mananciais, porque do jardim do Éden:

"saía um rio para regar o jardim e da. li se dividiu e se tornava em quatro braços"' (Gênesis 2,10)

e prossegue:

"e plantou o Senhor Deus um jardim no Éden, da banda do Oriente, e pôs ali o homem que tinha formado" (Gênesis 2,8)

por aí se vê que ele próprio fez o jardim e nomeou o jardineiro e, mais ainda, atribuiu-Ihe as devidas obrigações funcionais:

“e tomou o Senhor Deus o homem e o pôs no jardim do Éden para o lavrar e o guardar" (Gênesis 2,15).

Estavam assim definidas duas das funções necessárias ao jardim, a conserva e a vigilância.

Dentro desse quadro das reminiscências bíblicas infere-se ter sido o próprio Deus o primeiro paisagista e Adão o primeiro jardineiro.

E curioso que o vocábulo e a noção de paraíso figuram nos textos de dife: rentes religiões com o sentido de lugar de delícias, de sítio ameno, de vivenda dos bem-aventurados, salientando sua identificação como o lazer.

Ao mesmo tempo, e ainda pela Bíblia, encontramos que a sistemática é contemporânea dos atos iniciais da criação, pois, no terceiro dia, precisamente: 
"e foi a tarde e a manhã o dia terceiro"

isto é, Deus não realizou nenhum trabalho noturno, a criação sendo desenvolvida pela manhã e pela tarde; prosseguindo encontramos:

"e disse Deus produza a terra a erva verde, dando semente conforme a sua espécie, e a árvore frutífera, cuja semente está nela conforme a sua espécie. E viu que era bom" (Gênesis 1,12)

"e a terra produziu conforme Deus ordenou" (Gênesis 1,12).

Vemos assim que a mais antiga classificação botânica, apresentada no Gênesis, reconhecia ervas e árvores, todas com sementes. Ao que parece as samambaias e demais plantas sem sementes não chegaram a existir no Éden.

Mas, não é nosso objetivo continuar discutindo sobre esses curiosos textos bíblicos. Devemos aqui encarar o jardim não mais como objeto da criação, porém rigorosamente dentro de um ponto de vista histórico e reconhecer que representa $o$ jardim uma das mais antigas tentativas do ser humano de sobrepor à ordem natural a ordem humana.

É fato plenamente conhecido que o jardim, como realização social, retrata com fidelidade o estado cultural alcancado por uma comunidade.

Quanto mais elaborada e evoluída e estruturada uma cultura, maior requinte empresta às realizações jardinísticas.

Os jardins egípcios, os jardins da Babilônia, os jardins árabes de Sevilha e Granada, o jardim japonês e os jardins europeus (italiano, francês e inglês) exemplificam bem o que foi afirmado acima. Já as hordas bárbaras, os povos primitivos e os nômades desconhecem em absoluto o jardim.

A conceituação do jardim não é precisada nem em dimensão (um jardim pode ter qualquer dimensão), nem em forma. nem pela natureza de sua composição própria. Há mesmo exemplos de jardins sem plantas.

Fundamentalmente, o jardim corresponde a uma porção limitada do espaço, organizada finalisticamente para a amenização, o proveito, a educação, o lazer, o encontro ou à meditação e a contemplação daqueles que o frequientam.

O jardim é pois, numa formulação globalizante, uma expressão localizada e definida em termos de uso, da paisagem artificial, construída ou humanizada.

Teorizando sobre o jardim podemos dizer que três grandes parâmetros definem o jardim, o atendimento de finalida. des utilitária, lúdica ou cognitiva.

Porém não chegamos ainda a responder à indagação inicial, o que vem a ser um jardim botânico. Aparentemente o qualificativo serve como uma alterna. tiva frente a outro tipo corrente de jardim - o "jardim zoológico".

E de uso habitual a caracterização do "jardim botânico" como um tipo de jardim dotado de uma coleção de plantas organizadas obedecendo a critérios diversos, porém com finalidade científica. Enfim, e deve ser sublinhado, é impossível desvincular o "jardim botânico" de atividade científica ou cognitiva, cujo objetivo é conhecer a planta por ela própria, como um elemento extraído e isolado da realidade ambiental ou de sua posição na natureza.

Chegados a esse ponto vale acentuar a condição de ser vivo da planta. Assim ela pode sofrer abordagens de variadíssima natureza.

Podemos nos ocupar de sua posição no sistema de classificação, podemos decidir se ela já é conhecida ou nova para a ciência, estudar sua morfologia externa, seu dinamismo reprodutor, sua atividade fisiológica aí incluído seu crescimento, sua estrutura interna, com todos os requintes da microscopia moderna, sua composição química e todas as demais propriedades que constituem sua utilidade ou seja o uso humano. Em realidade os aspectos aplicados, embora não sejam de todo descartáveis, são melhor apreciados em outros campos de atividade humana como a agricultura, a tecnologia industrial ou a merceologia.

Mas, num rápido bosquejo, digamos algo sobre a origem e a história dos grandes jardins botânicos, em todo o mundo.

Os povos cultos da antiguidade tiveram jardins que se aproximam por suas funções do conceito de "jardim botâni$\mathrm{co}^{\prime \prime}$.

Assim há referências ao Imperador Chen Nung, cognominado "o orador divino", em época tão distanciada como o século XXVIII a.C., que manteve um jardim com finalidades experimentais. $O$ Faraó Tutmés III (1504-1450 a.C), que obteve importantes vitórias militares na Ásia, de volta de suas campanhas trazia plantas e animais introduzidos em jardins nos arredores do templo de Karnak, conforme o atestam os baixos-relevos ainda existentes. Na Assíria um soberano, Teglath Phalazar I (1112-1074 a.C.), outro grande conquistador, manteve em seu jardim uma coleção de plantas indígenas e outra de plantas exóticas, entre elas o cedro e trepadeiras raras. No continente americano, dentre os povos pré-colombianos, destacavam-se os astecas ou nahauatl que desenvolveram um notável interesse científico pelas plantas e, por ocasião da conquista por Cortés (1520), em nenhuma nação européia havia nada comparável ao extenso "jardim botânico" que os espanhóis então encontraram. Esse fato tem repercussões até o presente no México onde o gosto do povo pelas flores constitui uma característica nacional.

Devemos ao filósofo grego Aristóteles o mérito de haver fundado o primeiro "jardim botânico" do ocidente e a respeito do qual temos informações fidedignas. Era ligiado à escola de Aristóteles, o Liceu (ao pé do monte Licabeto), nome derivado do deus lobo (Lykos). Esse jardim foi legado por Aristóteles a seu discípulo Teofrasto, considerado o fundador da botânica científica e cognominado o pai da botânica e, sem dúvida, o maior botânico da antiguidade.

$\mathrm{Na}$ Roma antiga, os jardins botânicos eram utilitários e didáticos. Plínio, o Antigo, recomendava o jardim de um certo Castor, aos estudantes interessados.

Durante a Idade Média, os "jardins botânicos" eram jardins monásticos, vindos da época de Carlos Magno. A ciência de então era um monopólio dos monges e o caráter de "jardins botânicos" Ihes advinha de terem coleções para estudo. Em muito contribuíram para as ilustrações e os textos botânicos da época.

O fenômeno da urbanização, a ascen. são da burguesia e o conseqüente surgimento das universidades geraram como que um antagonismo frente aos mosteiros-fortalezas.

Porém, inicialmente, nas universidades predominava o argumento de autoridade e não era valorizada nem tavorecida a observação da natureza.

Dessa forma e por muito tempo ainda os jardins dos conventos seriam os centros de estudo e de cultivo de plantas.

Com o Renascimento há um florescimento das ciências da natureza, baseadas na observação direta. Iniciado na primeira metade do século XV, na Itália, essa onda cultural se espraia pela França e pela Alemanha. $O$ ciclo das viagens de descobrimento gerou um grande interesse 
pela introdução de plantas dos países até então não conhecidos. A taxinomia progride e busca novos objetivos apoiada em coleções de plantas, em "jardins botânicos" e na forma de materiais preservados (herbários).

Nessa fase, o primeiro "jardim botânico" no sentido moderno é fundado, em Pisa (1544), pelo Professor de Botânica de sua universidade, Luca Ghini (1490. 1556). Depois do de Pisa, surgem "jardins botânicos" em Pádua e Florença, todos decorrentes da benevolência da Casa de Médici. Nesse período é estabelecido o primeiro herbário, também em Pisa, por um discípulo de Ghini, o padre Michele Merini. $O$ jardim de Pisa não subsistiu, porém o de Pádua permanece até os dias atuais e no mesmo sítio.

Sucessivamente vão surgindo outros jardins, Bolonha (1547), Zurique (1560), Paris (1597), Oxford (1621), Berlim (1679), Edimburgo (1680) e Amsterdã (1682). O Jardim de Kew é bem mais recente (1760).

No Brasil, coube ao Príncipe Maurício de Nassau a glória de ter sido o fundador dos primeiros "jardins botânicos" e do primeiro "jardim zoológico", em terras americanas pré-descobrimento, no Recife, em pleno século XVII. Infelizmente esses jardins não subsistiram, destruídos que foram durante o assédio de Recife e as lutas pela reconquista lusobrasileira.

Ao final do século XVIII desperta Portugal para a necessidade de melhor ser conhecida a flora brasileira. Firma-se na metrópole uma atitude realista de atentar para os recursos naturais e para sua importtância.

Uma Carta Régia, de 04/11/1976, determina a criação de um "jardim botânico", em Belém. Teve 'efêmera duração, contudo cabe-lhe o mérito de ter sido o modelo para a criação de outros mais, em Pernambuco, na Bahia e no Rio de Janeiro, onde ora nos encontramos e cuja data natalícia ora festejamos. Em Vila Rica, a então capital do ouro e importante centro cultural, com um contingente de núcleos de apoio entre eles um teatro e um "jardim botânico" que atualmente, e em boa hora, é objeto de um trabalho de reconstituição. De todos esses apenas o do Rio de Janeiro logrou a estabilidade necessária para vencer os séculos, e é por isso que estamos agora aqui reunidos.

É curioso assinalar que no mundo de nossos dias quanto mais civilizados e culto um povo maior o número de "jardins botânicos" proporcionalmente a sua superfície territorial.

Assim, nos Estados Unidos existem, entre "jardins botânicos" privados e públicos, cerca de uma centena. A Inglaterra com uma área muitas vezes menor tem pelo menos $\mathbf{1 0}$ grandes jardins botânicos, em que se destacam como de excepcional valor os de Edimburgo e de Kew. Na França o número desses jardins anda em torno de 15, sendo que os de maior importância são os de Montpellier (1594) e de Paris. Na Alemanha são mais importantes os de Berlim, Duisburg, Munique, Dresden e Frankfurt. Rússia, China e Índia também possuem estabelecimentos categorizados.

Notável é a posição da Austrália com uma rede de estabelecimentos localizados nas principais províncias botânicas ou regiões ecológicas do país (Sydney. Brisbane, Adelaide, Melbourne, Camberra e Hobart, na Tasmânia).

Esta digressão teve o objetivo de realçar a importância para as grandes noções da atualidade na posse de "jardins botânicos".

E assim é chegada a hora de discutir as finalidades e o papel que devem assumir os jardins botânicos no mundo contemporâneo.

É sabido que os "jardins botânicos", mormente os grandes jardins tropicais de que o JB do Rio de Janeiro é um paradig. ma, ganham uma importância maior frente aos problemas da atualidade que o homem e a sua tecnologia vão criando dia após dia.

Em tempos anteriores prevaleceu uma concepção de que o "jardim botâni$c^{\prime \prime}$ seria principalmente um local de ver plantas, de reconhecer plantas, ao mesmo tempo que de entretenimento para o público. No começo deste século circulava o conceito de que sua coleção viva poderia ser organizada em três unidades básicas, uma primeira que buscava apresentar as plantas em ordem sistemática, como se possível fosse enquadrar a diversidade do mundo vegetal na exiguidade de uma área limitada e com condições ecológicas bastante uniformes. Outra parte abrigava as plantas por seus caracteres biomorfoló. gicos apresentando setores definidos como por exemplo plantas suculentas, trepadeiras, epífitas etc. Representa um maior grau de concessão ao natural. Finalmente uma terceira tenderia a apresentá-los em arranjo obedecendo à fitogeografia com a reunião de grupos integrados por elementos oriundos de uma mesma região com a apresentação de conjuntos de plantas da caatinga, da restinga, do cerrado etc., por exemplo.

Atualmente o planejamento dos "jardins botânicos" oferece maior liberdade, respeitadas a visão paisagística e a adequação ecológica das plantas respectivas. Isto é o que se cultiva nas condições em que vai ser cultivado. $O$ essencial é que o conjunto resultante configure uma aparência capaz de oferecer a seus visitantes emoções e prazeres do real valor intelectual e estético.

Porém, vejamos as finalidades de um “jardim botânico" na atualidade:

1) - Finalidade utilitária - um '’jardim botânico" se constitui desde logo em importante área paisagística de uma cidade oferecendo a seus habitantes o desfrute ambiental de contemplálo como área verde, área de pausa no congestionado tecido urbano. Nessa condição pode ter influência na arbo. rização pública indicando o que plantar e como fazê-lo. Contribui para a melhora das condições do ar urbano pela função clorofiliana de suas folhas. Os horticultores profissionais e os núcleos de ensino hortícola podem se beneficiar em alto grau de um intercâmbio e de um relacionamento com o "jardim botânico", recebendo sementes e materiais de propagação de plantas raras ou ameaçadas de extinção ou de que haja interesse em difundir para alguma outra finalidade. A manutenção de coleções de plantas ornamentais, de "cultivares" selecionados e de diversa natureza, de híbridos, de plantas modificadas por tratamentos químicos ou físicos são tarefas bem adequadas a essas instituições.

2) - Finalidade educativa - o "jardim botânico" pode participar do assistemático, pela massa de informações que oferece ao visitante de qualquer categoria, e do ensinc sistemático pelo oferecimento de cursos de diversas naturezas. Pode se dizer que ele é, em si mesmo, uma unidade polivalente de ensino. Ao freqüentá-lo, o público se instrui, aprende as mensagens de cunho conservadorista, e é introduzido na longa via do deleite através do uso estético das plantas. Atendendo ao nível pós-graduado o "jardim botânico" oferece condições de atendimento a um público difei ente forma- 
do pelos estudantes e interessados em produzir teses pós-graduadas e monografias diversas.

Não raramente os "jardins botânicos" encerram elementos relacionados ao patrimônio histórico cultural, como é o caso da primeira estátua fundida no Brasil ou da portada da Academia Imperial de Belas-Artes, incorporadas a este "jardim botânico". São bens a zelar cuidadosamente e a transmitir ao longo do tempo, de uma geração dos trabalhadores da casa às gerações subseqüentes.

Pode o "jardim botânico" abrir periodicamente suas instalações para apresentar ao público exposições especializa. das que despertam grande interesse, mormente por parte de colecionadores (orquídeas, flores-de-maio, samambaias, bromélias etc.). Estas exposiçães podem inclusive, por sua regularidade, virem a figurar nos calendários turísticos. Podem distribuir, por doação ou venda, folhetos, quadros, obras que contribuem para a elevação do nível de consciência do pú. blico, sobre os problemas dos recursos naturais.

A presença de um "jardim botânico", especialmente de um "jardim botânico" inserido no conturbado tecido urbano, representa uma área verde, um espaço não-construído, uma pausa, enfim. Ainda é o jardim botânico local de visita para estrangeiros cultos $e$ interessados em $\infty$. nhecer os elementos significativos do patrimônio vegetal brasileiro.

3) - Finalidade científica - a presença de um "jardim botânico" tem sempre influência sobre os estudos botânicos de qualquer natureza. A taxinomia, a anatomia, a fisiologia, a ecologia, a fitoquímica etc. e tantas outras dis. plinas botânicas usualmente têm apoio nas coleções vivas ou de materiais preservados. Toda a problemática de cultivar e de experimentação sobre plantas é grandemente benefia. da pela colaboração de um “jardim botânico".

Queremos insistir no papel do "jardim botânico" na defesa de espécies ameaçadas de extinção que podem melhor ser multiplicadas em condi. ções experimentais. Também é fundamental que essas plantas fiquem resguardadas no "jardim botânico" sob a forma de matrizes.

O "jardim botânico" tem papel saliente na preservação de coleções vivas de plantas de interesse genético, funcionando como banco de genes, e realizando permutas de material reprodutivo (especialmente sementes).

A estrutura de um "jardim botânico" exige como complemento indispensáveis ao desempenho de sua missão científica, uma série de elementos de apoio como o herbário, a coleção carpológica, o laminário, a xiloteca, a esporoteca, a biblio. teca, instalações para reprografia e fotografia, laboratório fitoquímico, sala de balanças etc., afora os apoios indiretos como os serviços de atendimentos aos consulentes e visitantes, bem como os quadros administrativos e auxiliares. Porém destaque especial merece o quadro dos cientistas e pesquisadores.

Um "jardim botânico" deve pesquisar e publicar os resultado obtidos. Deve atender às necessidades de pesquisa botâ. nica tão necessária a um país que é ou foi detentor da mais rica flora de um só país. Deve inclusive atender à principal dela que é a de manter um núcleo científico em evolução, propiciando a seus integran. tes condições de aperfeiçoar-se e de viajar pelo país e de visitar outros centros em países desenvolvidos.

Isto garante que os afastamentos por limite de idade, morte ou outras causas não irão criar os hiatos na trans. missão de experiência que tão nocivos tem sido ao desempenho de nossas instituições.

Isso permite a substituição por ele- mentos mais jovens, - porém já integrados à instituição e beneficiários de assistên. cia adaptativa e da orientação recebida de colegas mais avançados. $E$ toda a ins. trumentalidade da transmissão da expe. riência.

No mundo atual em cada "jardim botânico" faz-se necessário que as mentes esclarecidas de seu corpo científico devolvam o que lhes deu a comunidade em forma de esclarecimentos comunitários, e de uma posição definida em defesa da conservação do meio ambiente como um valor a sustentar, para que a vida continue a ter sentido nesse pequeno planeta.

Por fim conhecedor que sou da pre. sente base de recuperação deste "jardim botânico", depois de vencer outras fases não tão promissoras, isto me traz alguma tranqüilidade.

Uma última consideração, creio que nesta hora é oportuno encarecer que os órgãos de suporte à pesquisa se movimentem em favor de medidas para a ampliação e o rejuvenescimento de seus quadros. É preciso considerar que pesquisa é a obra do pesquisador. O mais rico herbário e a mais bem-aprovisiona. da biblioteca não fazem ciência por si só e que o "jardim botânico" sem atividade científica poderá até ser um local belo e ameno, mas não será mais um "jardim bo. tânico".

É preciso dizer que no caso brasileiro as tradicionais instituições de pesquisa como este "Jardim Botânico" e o "Museu Nacional" devem, em nome da integração da cultura nacional, serem alvos de um tratamento especial e adequado, longe das rotinas de uma burocracia superlativa e fastidiosa.

A nossa mensagem final nesta tarde aconchegante de junho é um cumprimento às autoridades que o administram, a seu corpo científico, aos dignos corpos administrativo e auxiliar e aos jovens estagiários que são, no presente, os representantes de um futuro que se aproxima velozmente.

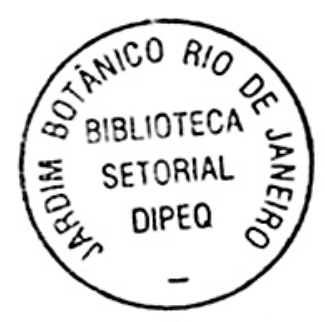

